\title{
Possibilities of use of Free and Open Source software in the Greek local authorities
}

\author{
Stavros Koloniaris , George Kousiouris and Mara Nikolaidou \\ Department of Informatics and Telematics.Harokopio University of Athens, 9, Omirou Str. \\ 177 78, Tavros \\ \{skoloniaris, gkousiou, mara\}@hua.gr
}

\begin{abstract}
Use of Free and Open Source software has started to get an increased level of functionality and trust, following the existence of a variety of solutions and supporting communities across the Web. In this paper, the current penetration and usage of Free and Open Source Software in the municipalities of Greece was recorded, as well as its potential especially when compared with the current state of computerization and hardware level. Conclusions were drawn on whether the municipalities will benefit from the usage of Free and Open Source Software, in technical and financial terms, as well as proposals are submitted in how the municipalities can benefit from an uptake in technology (especially Cloud computing), given their existing IT staffing and municipality organization. The possibility of improving the provided services to the citizens by using this software is also examined as well as cost aspects that can be improved.
\end{abstract}

Keywords: free and open source software, adoption, municipalities, government, survey, cost analysis

\section{INTRODUCTION}

The municipalities of Greece provide a variety of services to their citizens and perform different processes within their responsibilities and obligations. All their processes involve and use an IT sector in order to provide the required services. Although the computerization of the Greek municipalities and the usage of IT infrastructure to perform their operations is not something new, most of them fail to use modern technologies and are bind to proprietary software and high specification hardware. This leads them to have an increased operational cost,which eventually bounces to the citizens.

Furthermore, because of the ongoing economical crisis, the budgets of the municipalities are decreased and the available funds that can be invested in IT are cut-off to minimum. Many local authorities are forced to operate with old infrastructure and abolished or near end of life cycle software. This situation puts them in high risk, since they become vulnerable to hacking operations and exploits, risking to lose funds and data of their citizens. 
In the year 2009 the total budget of all 325 Greek municipalities for IT expenses, including both hardware and software, was 22,409 million euro for buying new equipment and software plus another 5,985 million euro for service and updating purposes of the existing software. Those amounts are no longer available thus it became essential to find a way to continue providing the same, or even better quality of services to the citizens, by using late software but in decreased cost. Another goal is to increase the life time of the existing hardware so that it will not need an upgrade or replacement for a longer period of time.

The use o Free and Open Source Software may be the answer to this quest and the purpose of the current research is to evaluate the benefits and profits that the municipalities will enjoy from the usage of FOSS in relation to the risks that they must take and the dangers that they may encounter. By following the example of other European municipalities, such as Munich in Germany, and great organization, such as NASAs, or even Governments, such as China, the Greek municipalities may become able to save resources for using them in more crucial sectors.

\section{INFORMATION GATHERING AND COMPUTATIONAL DETAILS}

\subsection{Questionnaire creation}

There are no official records on each municipality's existing infrastructure, since they were free to call for offers and choose the winner on their own, according to their needs and pursuits. This happens for both hardware and software, so the municipalities may perform the same operations in different ways, using totally unique compilation of hardware and software.

In order to gather and organize such kind of information, a questionnaire was created that was directed to each municipalities IT department. The purpose of this questionnaire was to gather information on the existing hardware infrastructure of each municipality, the existing software in use as well as the reason it is used for, the knowledge that the IT department's employees have on modern technologies and the ability they could have on deploying those technologies and support its usage.

\subsection{Questionnaire creation}

The questionnaire that was created was intended to be anonymous and the participants were all invited to participate via personal telephone communication with the head of each municipality IT department. There was a field were the participant was asked to reveal the municipality where he is employed but that was just to ensure that there are no double answers to the questionnaire from the same municipality.

The questionnaire had six sections:

Section 1, Utilized Hardware: In the first section the participant was invited to list the hardware specifications of the personal computers that are used in the municipalityThe speed of the structured network wiring was answered in this section 
as well. The purpose of those questions was to estimate the remaining lifetime of the hardware and to check the probability of extending its lifetime through the use of free and open source software. The network speed that the cabling could offer would help to check the probability of using network or cloud services.

Section 2, Utilized Software: Information about the installed operating systems and the proprietary software that it is being used was gathered in this section.The information gathered was used to check if there is free and open source software that could provide the same usability whilst being less resource consuming than the proprietary software.

Section 3, Provided Services: The third section had questions about the backbone of the municipality's infrastructure. The participants gave information about the servers their municipality has and the services that they offer to the rest of the departments. The purpose was to check the estimated life span of the servers hardware and the probability of using free and open software to expand their usability. This section also helped to check if the municipalities use centralized services and services provided through network in any of their activities.

Section 4, Cloud: The questions of this section were about cloud based services and technologies. The purpose was to check the degree of penetration of cloud computing in the municipalities and to identify the difficulties that occur when trying to implement cloud based solutions in the municipalities.

Section 5, Support Plan: In this section were gathered information about each municipalities IT support plan and the cost of it. The purpose was the see if there are possibilities of lowering the support cost by providing network or cloud based services and by using free and open source software.

Section 6, FOSS: The last section of the questionnaire was intended the check if the IT departments employees of each municipality have the knowledge and the ability to learn, deploy, use and support free and open source software. Some opinions on what are the factors of success or failure in using free and open source software were gathered in this section.

The questionnaire itself was accessible online and created by using a free and open source platform (Lime Survey). All questions were optional while partially completed questionnaires were also acceptable.

\subsection{Contact establishment}

Greece has 325 municipalities. The participants were contacted via telephone and a link to the questionnaire was sent to each one of them to the e-mail address that they provided. The contact period was from early to end of June 2017, while the questionnaire was online and accepting answers up to the end of July 2017.

There was no success in communicating with 55 of the municipalities IT department. In those cases, a link of the questionnaire was sent to the main e-mail address of the municipality, with a kind request to be forwarded to the IT department.

There were also 99 municipalities that stated they do not have an IT department and the support comes completely from an external associate. 


\section{RESULTS AND DISCUSSION}

\subsection{Participation and statistics}

The goal was to gather at least 30 participations in the questionnaire. When the answering period ended there were 61 full answers to the questionnaire plus additional 59 incomplete answers. The above accomplishment gave the possibility to continue the research by taking in mind only the completed answers, while the incomplete were studied in some cases to gather additional information but mostly for statistic reasons.

From the 61 complete answers there were 7 that the participant did not share the name of the municipality to which they are employed. The remaining 54 municipalities have a combined population of 2.554 .332 citizens which is the $23,62 \%$ of the total population of Greece. Furthermore, the total number of computers that those municipalities have deployed in their departments is 8.750 PCs.

99 of the municipalities that were contacted stated that they do not have an IT department which means that at least $30 \%$ of Greece's local authorities are depended on an external partner to provide them with IT support.

Table 1: Contact and answer details

\begin{tabular}{|l|l|l|l|}
\hline Contacted & $\begin{array}{l}\text { Complete } \\
\text { Answers }\end{array}$ & $\begin{array}{l}\text { Municipality } \\
\text { Percentage } \\
\text { (Complete } \\
\text { answers) }\end{array}$ & $\begin{array}{l}\text { Population } \\
\text { Coverage }\end{array}$ \\
\hline 325 & 61 & $18,7 \%$ & $23,62 \%$ \\
\hline
\end{tabular}

\subsection{Absolute numbers and cost calculations for workstations}

The 61 IT departments declared that their municipalities have a total of 8.750 computers deployed. About 1.108 of those are running on an Intel Pentium or a corresponding to that generation AMD processor, which means that they are over 15 years old. Another 3.066 computers are equipped with an Intel Core, Core 2, Core 2 duo processor or an equivalent AMD processor, aged at about or over 10 years.

When checking the installed memory on each of those computers, there are 2.386 computers than have $2 \mathrm{~GB}$ or less RAM installed, and another 1.229 computers that have $1 \mathrm{~GB}$ or less installed.

It is the logical continuity of the above computer specification, that there are 2.003 computers that their operation is based on Microsoft's Windows XP or Microsoft's Windows Vista, which operating systems are already been abandoned and not supported or updated any more. Furthermore, there are 2.738 computers that operate on Microsoft's Windows 7 or Microsoft's Windows $8 / 8.1$, which operating systems are closing to their end of life cycle, since their mainstream support has ended and they are closing to the end of their extended support. 


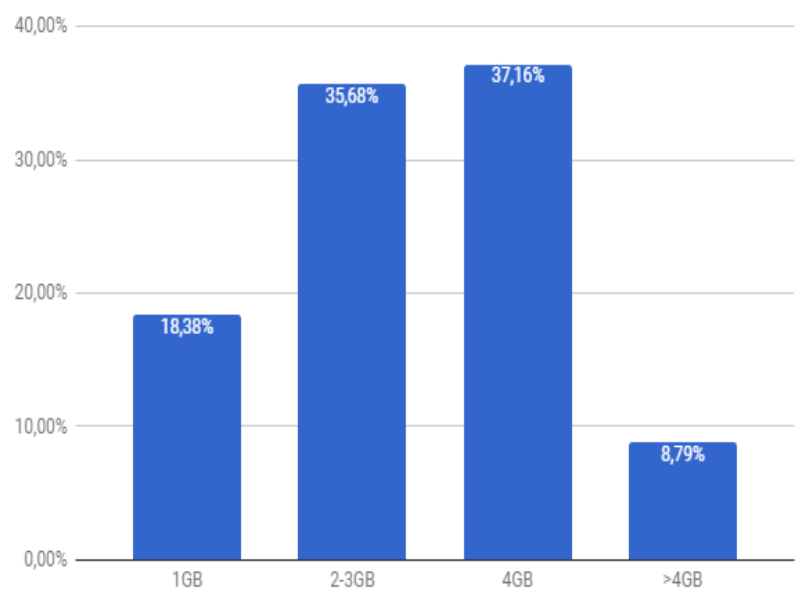

Figure 1: The percentage of RAM availability in municipality workstations

All the above conclude that over half of the existing workstations need an urgent upgrade or will soon need an upgrade, on either their hardware, their operating system or both.

The upgrading cost for hardware is estimated to be over 1.500 .000 euro and the cost of new licenses for the later operating system would be another 784.500 euro.

Table 2: Number and upgrade cost of workstations

\begin{tabular}{|l|l|l|l|l|}
\hline \#Workstations & $\begin{array}{l}10 \text { years and } \\
\text { older }\end{array}$ & $\begin{array}{l}\text { Cost of H/W } \\
\text { upgrade }\end{array}$ & $\begin{array}{l}\text { Cost of OS } \\
\text { S/W upgrade }\end{array}$ & $\begin{array}{l}\text { Cost of Other } \\
\text { S/W (estimated) }\end{array}$ \\
\hline 8750 & $\begin{array}{l}4741 \\
(54,18 \%)\end{array}$ & $1.500 .000 \mathrm{E}$ & $784.500 \mathrm{E}$ & $3.512 .650 \mathrm{E}$ \\
\hline
\end{tabular}

Furthermore, most of the computers of the local authorities have installed proprietary software that serves the needs of their day-to-day operation. Almost all IT departments mentioned that their computers have an office suite installed, with Microsoft's Office in all of its versions being the most popular, while there are some municipalities that use a mix of proprietary and FOSS suite having Microsoft's Office and Libre/OpenOffice simultaneously. Other proprietary software that it is used includes but is not limited to client-based antivirus program, from vendors such as ESET, Kaspersky, Panda and Symantec, a file compression manager, mostly WinRAR, a PDF creator and manipulation tool and a CAD suite, mostly Autodesk's AutoCAD.

The number of computers that have the above mentioned software installed is not clearly declared, but it could be assumed that at least half of those computers have a Microsoft's Office Suite and a client-based antivirus. It could be also assumed that $25 \%$ of those computers have a proprietary PDF creator/manipulation program and a proprietary file compression manager. Lastly, it could be assumed that an average of 3 computers per municipality have a CAD suite installed. Under all the above assump- 
tions, the estimated cost of the installed proprietary software raises up to 3.512.650 euro, which is the cumulative amount that will need to be spent over time when these programs need to be upgraded. It should be mentioned that some of those programs, such as the CAD suite and the antivirus suite, operate on yearly subscription and a continuous renewal of a 5 year period was assumed in order to calculate the cost of those programs.

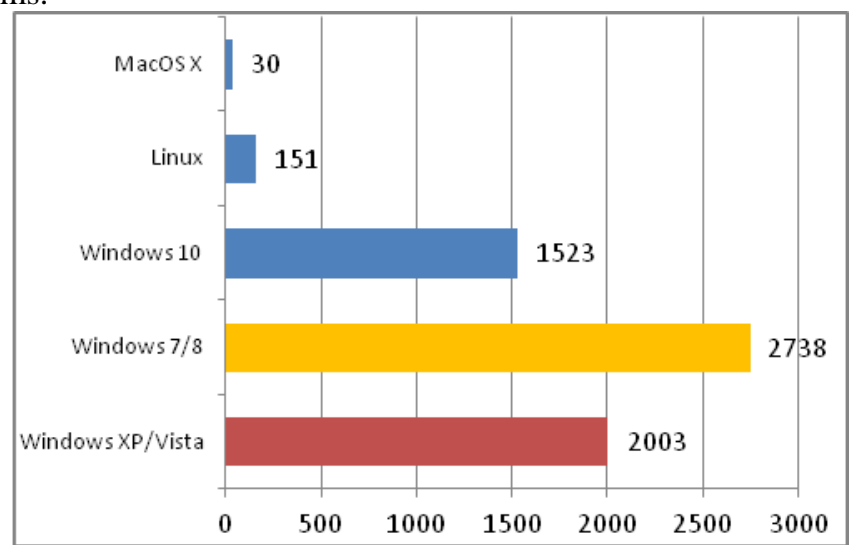

Figure 2: Operating System usage in workstations (No longer supported versions in red, near end of life versions in yellow)

Besides the above, a series of more purposeful software where mentioned. Those included programs that served the needs of warehouse management and logistics, financial management, civilian communication and complaints recording, e-protocol, HR and payroll, public works monitoring. The cost of this software is unclear since they are offered as "by request", according to the needs of each organization, the components that should be bundled to it and the support plan that will accompany it.However, even though an estimation of their cost cannot be accurate, it cannot be considered negligible and proposals on alternatives should be made for these programs as well.

\subsection{Absolute numbers and cost calculations for Backbone Infrastructure}

Besides workstations, the questionnaire asked for information about the backbone infrastructure of the municipalities. In the municipalities that answered the questionnaire there are 312 servers offering services to the workstations.

There are 6 of the 61 municipalities that still use a server which operates on Microsoft Windows NT/2000 server edition and another 33 that operate on Microsoft Windows Server 2003, including all of its versions. The support for those operating systems has already ended and no service packs or updates of any kind have been released for them in many years, which render them vulnerable to modern security and operational dangers.

Furthermore, there are 40 municipalities that still have servers operating on Microsoft Windows Server 2008, an operating system that in most of its versions is not 
supported any more, while the versions that are still supported are closing to their extended support end date.

Of the municipalities that answered, 21 have deployed servers running Microsoft Windows 2012 server, including all versions, and only 3 have servers running Microsoft Windows 2016 server. Lastly there are 15 municipalities that have deployed servers running a Linux Server distribution.

The servers are used to provide various services to the departments of the municipality and to the citizens in some cases. Some of those services are file (storage) services, backup services, database and other application services.

\begin{tabular}{|l|c|c|}
\hline Service provided & Answers & Percentage \\
\hline File (Storage) services & 40 & $65,57 \%$ \\
\hline Printing Services & 13 & $21,31 \%$ \\
\hline Backup Services & 39 & $63,93 \%$ \\
\hline Virtualization (VMs) & 22 & $36,07 \%$ \\
\hline Web Services & 31 & $50,82 \%$ \\
\hline Application Services & 38 & $62,30 \%$ \\
\hline Mail Services & 13 & $21,31 \%$ \\
\hline Database Services & 43 & $70,49 \%$ \\
\hline Other & 2 & $3,28 \%$ \\
\hline
\end{tabular}

Figure 3: Services provided by municipality servers

By assuming that one third of the servers are operating with an older operating system that needs replacement, the cumulative cost of the licenses is estimated to be at 99.088 euro, which does not take into account the extra cost of the required service packages that are needed in each case or the hardware upgrades that should be done beforehand.

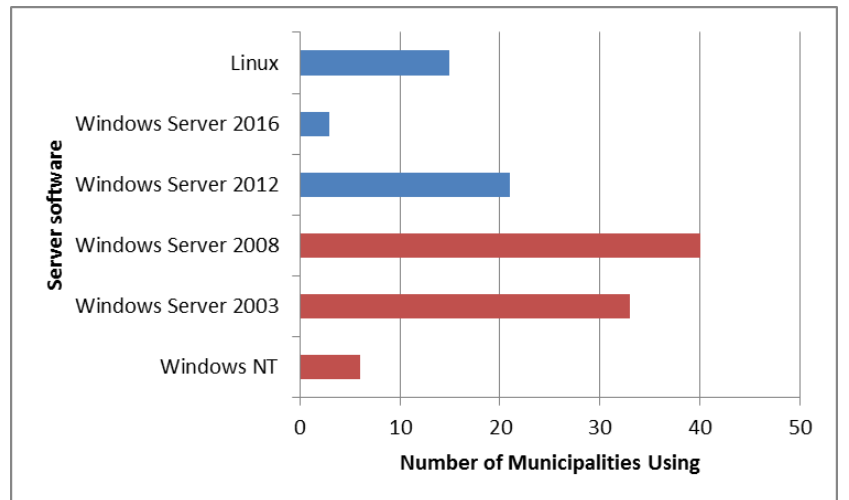

Figure 4: Used OS on Municipality Servers (in red the no longer supported versions)

On examining the existing structured network installation, most of the municipalities have a 1000BASE-TX (Gigabit Ethernet) infrastructure and only 12 of them, mostly small in population and coverage area or near the borders and island municipalities, 
are still operating on 100BASE-TX (Fast Ethernet) network infrastructure. In most use cases the Fast Ethernet infrastructure could be considered to be sufficient, but surely an upgrade of this infrastructure would be needed if a complete server-based or cloud-based implementation would be deployed in the future. In this scenario the largest municipalities would need to upgrade their Gigabit Ethernet infrastructure to fiber optics in order to not suffer from network delays and bottleneck phenomena.

\subsection{Cloud computing in the municipalities}

The survey also examined the knowledge and the familiarity that the IT department's employees have with the concepts of cloud computing, as well as the existence of any such a service in their municipality.

The answer to the question of knowledge and familiarity was unanimously affirmative but the deployment statistics are discouraging. Only 4 of the municipalities provide public cloud services to their departments and another 11 that provide private cloud services. Most of these implementation are used for file sharing through remote departments of the municipality.

Nevertheless, the majority of the respondents believe that cloud services could and should be offered in order to achieve lower operational costs and take advantage of the benefits that this technology has to offer, such as scalabilityand operating system independency. However, there are still concerns about the data safety that a cloud implementation could provide and the fact that a device has to be online in order to operate on cloud basis

\begin{tabular}{|l|c|c|}
\hline Cloud services offered & Answers & Percentage \\
\hline Yes, via public cloud & 4 & $9,84 \%$ \\
\hline Yes, via private cloud & 12 & $21,31 \%$ \\
\hline No & 37 & $60,66 \%$ \\
\hline
\end{tabular}

Figure 5: The percentage of municipalities that offer cloud based services

\subsection{Free and Open Source Software (FOSS) in the municipalities}

The main purpose of the current research was to determine if it is possible to reduce the cumulative cost of computerization of a municipality by using Free and Open Source Software. So it was essential to check the experience that the IT department's employees have on FOSS.As in the cloud section, all the respondents replied that have knowledge of what is FOSS but only 34 of them stated that there is somefamiliarization of IT department's employees with FOSS.

Only 35 of them stated that they use some kind of FOSS in their organization and that is mainly limited to the use of a FOSS office suite such as Libre/OpenOffice. Some of them use a FOSS mail client (Mozilla Thunderbird), alternative internet browsers (Google Chrome, Mozilla Firefox) and a CMS (Joomla, Wordpress). Once again it is clear that the penetration of FOSS in the Greek municipalities is at an early stage and that they are bind to proprietary software in order to operate. 
When asked if the change from proprietary to Free and Open Source Software would be possible and would have positive effects to their organization, only 22 of the respondents replied positively. Even worse is the belief that a change to the use of FOSS will not be accepted by the end users (resistance to change phenomena) since only 10 participants though that this is likely to happen without the occurrence of any major problem.

\begin{tabular}{|l|c|c|}
\hline \multicolumn{1}{|c|}{ Advantages of using FOSS } & Answers & Percentage \\
\hline Small or no cost & 37 & $60,66 \%$ \\
\hline $\begin{array}{l}\text { Lower hardware requirements and } \\
\text { greater durability }\end{array}$ & 11 & $18,03 \%$ \\
\hline $\begin{array}{l}\text { Existence of active communities that } \\
\text { support and evolve the available soft- } \\
\text { ware }\end{array}$ & 28 & $45,90 \%$ \\
\hline $\begin{array}{l}\text { Faster incorporation of software inno- } \\
\text { vations }\end{array}$ & 10 & $16,39 \%$ \\
\hline $\begin{array}{l}\text { They are easily customizable and can } \\
\text { be optimized to the individual needs of } \\
\text { each user }\end{array}$ & 9 & $14,75 \%$ \\
\hline $\begin{array}{l}\text { Easy functionality expansion by adding } \\
\text { modules }\end{array}$ & 17 & $27,87 \%$ \\
\hline $\begin{array}{l}\text { Plaethora of available tutorials as well } \\
\text { as online community support }\end{array}$ & 14 & $22,95 \%$ \\
\hline
\end{tabular}

Figure 6: Believed advantages of deploying and using FOSS

On the more technical and financial side the most favored factors that would lead FOSS to be successfully accepted in a municipality was considered to be the low or no cost of acquisition and maintenance of this software and the continuous upgrades that those software obtain through their supporting companies or the user communities. On the contrary, the main reasons that would lead such an attempt to failure where considered to be that FOSS software does not provide out of the box full functionality and that there are is insufficient training in usage of FOSS since there are not known certification programs that provide such kind of training. High favored reasons of failure where also the belief that support of FOSS is often insufficient and that the communities that develop and maintain FOSS cannot provide the same degree of security that a commercial company does at all levels of software support.

Through the communication that was made with the IT departments that eventually involved in the current research and answered the questionnaire, there was another conclusion made, that beyond the resistance to change phenomena, which includes the end users, there is also a fear of the unknown, which concerns the IT departments employees. Most of them have been skeptical and doubtful about the possibility of a radical change in the way they work and support their departments and the possibility that they would be requested to learn and support something totally new. 


\begin{tabular}{|c|c|c|}
\hline \multicolumn{3}{|l|}{ Disadvantages of using FOSS } \\
\hline & Answers & Percentage \\
\hline Inadequate support & 19 & $31,15 \%$ \\
\hline Insufficient documentation & 14 & $22,95 \%$ \\
\hline They do not provide full functionality & 25 & $40,98 \%$ \\
\hline Insufficient training in FOSS and lack of certifications & 21 & $34,43 \%$ \\
\hline $\begin{array}{l}\text { Does not integrate innovations and is evolutionarily behind } \\
\text { commercial competition }\end{array}$ & 10 & $16,39 \%$ \\
\hline $\begin{array}{l}\text { User communities do not provide the security provided by a } \\
\text { commercial company at all levels of software support }\end{array}$ & 19 & $31,15 \%$ \\
\hline
\end{tabular}

Figure 7: Believed disadvantages of deploying and using FOSS

\subsection{Software support plans}

Lastly, the cost of the existing software support plans was examined as well as the involvement of external supporters. Apart from the 99 municipalities that do not have an in house IT department and are totally dependent on support from external partners, all of the municipalities that have such a department and answered the questionnaire have a support plan that involves someone from outside the municipality itself. 48 of them gave an estimation of the current financial year budget for software support and the sum is over 1.650 .000 euro.

The majority of the municipalities have a maintenance/support contract with an external partner concerning the provided software. Since the involvement of the IT departments in supporting the proprietary software seems to be minimal, it is no surprise that there are no complaints concerning the functionality of the used software. Only 13 are concerned about the reduced functionality that the software in use provides, compared to the required one, and even fewer state that the current software cannot be upgraded due to its high cost

\section{PROPOSALS THAT INCLUDE FOSS AND USAGE OF MODERN TECHNOLOGIES}

\subsection{Operating Systems and commonly used software}

About half of the computers that exist in the participating municipalities are over aged and unable to run the modern proprietary operating systems and software efficiently. Although the minimum requirements of modern proprietary operating systems are relatively low, they still require more resources than the available modern free operating systems. In addition, the cost difference makes the free operating systems a fine choice.

There are some choices of free operating systems, with the Linux family being the most popular and better supported, while BSD and Solaris are yet excellent choices. Linux has been around for over two decades now and has dominated as an operating 
system for web servers, mainframes and supercomputers, but still its acceptance for desktop, workstations and everyday use computers is relatively low. Nevertheless it makes an excellent choice for public sectors workstation since some of the most popular distributions have very low hardware requirements making it ideal for use in older computers. Modern distributions deployed with an LXDE or XFCE desktop environment can be efficiently used in a 20 year old, Pentium 4 era, computer with as low as $256 \mathrm{MB}$ of RAM. Furthermore, the most popular distributionsoffer long term support (LTS) versions of their operating systems that are actively supported with updates for up to five years.

\begin{tabular}{|c|c|}
\hline \multicolumn{2}{|c|}{ Hardware requirements comparison } \\
\hline Windows 10 & Lubuntu 17.10 \\
\hline $\begin{array}{l}1 \mathrm{GHz} \text { processor or faster, 32 } \\
\text { or 64 bit; }\end{array}$ & $\begin{array}{c}512 \mathrm{MHz} \text { processor or faster, } \\
32 \text { or 64 bit; }\end{array}$ \\
\hline $\begin{array}{l}1 \mathrm{~GB} \text { of RAM for the } 32 \mathrm{bits} \\
\text { version, or at least 2 for the 64 bit } \\
\text { version; }\end{array}$ & $512 \mathrm{MB}$ of RAM; \\
\hline $\begin{array}{l}16 \mathrm{~GB} \text { of hard drive (32 bit) or } \\
20 \mathrm{~GB} \text { (64 bit); }\end{array}$ & $6 \mathrm{~GB}$ hard drive; \\
\hline $\begin{array}{l}\text { Graphics card that supports Di- } \\
\text { rectX 9 with WDDM 1.0 } \\
\text { controler or superior }\end{array}$ & no fancy graphics \\
\hline
\end{tabular}

Figure 8: Hardware requirements comparison between Windows 10 and the later Ubuntu Linux with LXDE desktop environment

Most of Linux distributionscome with preinstalled packages that serve the everyday use needs while there is a plethora of alternative software to be freely obtained and used through its public repositories.

A more precise approach that could cover most use cases that where proposed from the respondents is the use of an Ubuntu Linux distribution with a lightweight LXDE graphical environment (Lubuntu) loaded with LibreOffice as an office suite and PDF editor, Peazip as an archive manager, LibreCAD as a CAD suite and ClamAV as an antivirus suite, although an antivirus is probably not needed at all. There are many more alternative programs that can be used to serve the same purposes and that makes the current proposal to be one of the many available choices. There is also proprietary software available for Linux operating systems that may offer a different use experience than the free ones and are usually offered in affordable prices.

The majority of these programs are compatible with their proprietary rivals and the exchange of produced files between them rarely produceproblems that cannot be easily addressed. Furthermore, the modern look of the graphical environment can be modified and disguised in such a way that the end user will not easily realize the difference, making it easier to bend their resistance to change. 
The implementation of the current proposal can lead to savings, counted in millions of euro, amounts of funds that can be utilized in other areas of the municipality's activities.

\subsection{Purposeful software}

User communities that are involved in software development have produced a huge variety of programs that serve the needs of practically every user and organization. Most of them are given s open source which means that they can be freely altered and adjusted to the needs of the organization.

There are free and open source programs that can cover the needs of all areas of activity of a municipality. In context of the current research it was considered to be inappropriate to directly compare the used software with FOSS, since there were no records on specific usage that each of the proprietary software served and the way it is utilized and used in each municipality. A more thorough research would be needed in order to determine the true intended usage of this software in order to safely propose alternatives.

Nevertheless, honorable mentions should be made on free and open source software that serve the generic needs that where discussed. Those include but are not limited to OrangeHRM as an HR management software, Scriptum as an e-protocol, OpenWMS as an warehouse management, GnuCash and Eqonomize as a financial and accounting software, SuiteCRM, OpenBravo as an ERP solution. There are many more available options that can be freely obtained, examined, altered and used, whilst many of them can be utilized in server-client or even cloud basis and used through a web browser, making it unnecessary to install them separately on each workstation while its maintenance would be easier.

\subsection{Server Operating Systems and software}

As already mentioned, Linux is the dominating operating system used in web servers, mainframes and supercomputers worldwide. Obviously, it is considered to be the most secure and stable choice for such a purpose and there are major companies that have their Linux server releases available offering alongside with them support plans on demand.

The hardware requirements for Linux servers are so low that it can even be deployed on a 20 year old PC, so the existing hardware could be used as is without the urgent need of any upgrade. The basics services that a server should offer are easily triggered, including file (storage) services, backup services, mail services, printing services and web services. Other services can be deployed as well, including those that were mentioned as purposeful software and can be offered in a server-client basis. Virtual machines can also be deployed, using FOSS such as KVM or Xen.

Furthermore, the existing server infrastructure can be used to deploy private cloud and offer remote services to the municipalities departments. There are tools available that can help deploying and managing cloud services such as the OpenStack, Kubernetes, Juju etc. There are also new technologies emerging, such as containeriza- 
tion, that are even more lightweight and help provide more services without the need of new and powerful hardware. The use of a FOSS tool such as Docker for this purpose will help even more in keeping the current hardware operational without the need for its upgrade or replacement.

Most of the servers maintenance procedures can be executed remotely, so even if the municipality does not have an IT department or its employees do not have the ability to operate in a Linux server environment, those procedures can be executed from afarfrom a cooperating department of another municipality.

\begin{tabular}{|l|c|c|}
\hline \multicolumn{2}{|c|}{ Server OS comparison } \\
\hline Cost & Windows & Linux \\
\hline User interface & Per user license & $\begin{array}{c}\text { Free with support plans availa- } \\
\text { ble }\end{array}$ \\
\hline Remote access & Graphical & Command line \\
\hline Software availability & $\begin{array}{c}\text { Not available by default, needs } \\
\text { supported proprietary software is }\end{array}$ & $\begin{array}{l}\text { Integrated (terminal \& shell) } \\
\text { not ported to Linux but there is a } \\
\text { big amount of FOSS available }\end{array}$ \\
\hline Hardware support & Usually supported by OS & $\begin{array}{l}\text { There is a latency in porting } \\
\text { drivers for newer devices }\end{array}$ \\
\hline Safety & $\begin{array}{c}\text { Open to users, very prone to er- } \\
\text { rors, very likely to be attacked } \\
\text { tem settings, security holes and } \\
\text { vulnerabilities are corrected imme- } \\
\text { diately }\end{array}$ \\
\hline Support & Long term support available & $\begin{array}{l}\text { Varies depending on distribution } \\
\text { and version }\end{array}$ \\
\hline Documentation & Well documented & $\begin{array}{l}\text { Complete source code of the } \\
\text { system, API, libraries, and applica- } \\
\text { tions available: MAN and Info } \\
\text { pages }\end{array}$ \\
\hline
\end{tabular}

Figure 9: Server OS feature comparison

\subsection{Cloud computing utilization possibilities}

Cloud technologies are far from known to the Greek municipalities. None has implemented a cloud based approach and the only usage of commercial cloud services seems to be for file sharing purposes. Through the questionnaire it became clear that there is confusion between the concepts of server-client basis services and cloud services.

However, there is a prospect for the development and usage of cloud services in the Greek municipalities.A prospect that would lead to a technological leap and would dramatically reduce the need for powerful and expensive hardware, cost-effective software and continuous on-site support. Since the services would be offered remotely there will be only a need for internet-connected hardware. Most services could be offered as web-based services, so the need for purposeful software will be also reduced since a simple web browser will be enough to do the work. 
There can be two possible scenarios for adopting the cloud computing technologies. The first is that every municipality deploys its own cloud network using the existing hardware and the available software that has already been proposed. In this case, each municipality would be free to adopt a plan differently from the others, having the ability to differentiate its implementation according to the specific needs it may have. A team of able IT specialist would be needed in order to work on the project, a team that would have to be outsourced, if there are no availableand adequately qualified human resources from within the municipality's IT department. According to this plan there would be a need to deploy up to 325 private cloud networks, one for each municipality, and up to the same number of IT supporting teams would be needed in order to ensure its continuous operation. The cost for such an approach would be discouraging for the smaller municipalities that luck the funding or do not have capable teams for working on such a project.

The second scenario would involve higher authorities from the municipalities, in order to create a centralized cloud infrastructure that would serve the needs of all municipalities in the same distinct way, with little choices of differentiation.

The local authorities in Greece are divided into two levels. The first level includes the municipalities themselves and the administrative body of the Central Union of Municipalities of Greece. The second level includes the thirteen administrative regions of Greece, that each includes regional units which are further subdivided into the municipalities.

A cloud network could be created in each of the administrative regions, serving the needs of its municipalities. In this way the need for hardware and specialized personnel for the implementation of the cloud infrastructure would be decreased to 13 and only a small supporting team would be needed in each municipality. Furthermore, a totally centralized cloud infrastructure could be implemented under the responsibility of the Central Union of Municipalities, an infrastructure that could be based in the Unions headquarters and from there to serve the needs of all municipalities all over Greece.

In this way all municipalities would benefit since they all wouldbe able to use new technologies, to unify, consolidate and automate their processes and offer the same services to all citizens. There would be a need for a team in charge of assuring the central cloud infrastructure operation and care for its maintenance. There will be no need for large support teams in the municipalities since most of the operations would be held and executed on the cloud. It is even possible under certain circumstances for only a team of supporters per administrative region to be enough.

An estimation of the cost for such an infrastructure would be around 800.000 euro, a cost that is very small considering the annual spent of the municipalities towards their existing infrastructure. The annual operational cost of the cloud would be around 150.000 euro, including the power and cooling costs. The municipalities themselves would only need active internet connections and hardware able to connect to it, making most of the existing hardware enough for the purpose. The cost for software could be reduced down to zero, with the exception of some software that may not have alternatives on FOSS repositories. A support plan for the software is not calculated in 
the above estimation, and if one is needed its cost would probably not exceed the sum of 25.000 euro annually.

Furthermore, the cloud can offer increased levels of security, reliability scalability, manageability and immediate upgrades for all municipalities simultaneously. Also, such an attempt would offer possibilities of centralized management of request and processes as well as more efficient gathering of data necessary for analysis, statistics and future planning.

The whole plan implies the agreement of all municipalities and the definition of a joint action plan with a view to create a cloud computing infrastructure that will operate according to the overall needs of all municipalities and that will eventually benefit them all equally, with the ultimate goal being the citizens satisfaction from providing cost effective and more efficient services to them.

\section{CONCLUSIONS}

The computerization of the Greek municipalities is still in a stage that can be characterized as "early", while the used hardware and software resources are considerably out of date. There is a need of adopting new technologies that will raise the quality of the provided services to the citizens while lowering its operational and maintenance costs.

The usage of Free and Open Source Software locally is the first step to such an attempt, while the creation of a cloud infrastructure that would serve the needs of all municipalities is the ultimate goal. Especially for the latter, it could also hide the performance drawback of the ageing workstations as well as act as a centralized point of security given their vulnerabilities due to no longer supported software versions. Based on the municipalities characteristics and available IT resources, two separate proposals were considered, one based on the overall regional administrative areas and a centralized one.

For the FOSS case, except for the obvious cases of OSs, Office suites and antiviruses, the use can be easily extended to more advanced software such as CAD, HR, ERP, CRM and e-protocol based solutions, whose commercial licensing costs equivalents are also considerably higher.

The combination of FOSS and Cloud technologies would give to the municipalities bleeding -due to the continuous crisis- economy a surplus of about 5 million euros that can be used in other areas of competence. Setting a common goal and the cooperation of all stakeholders is essential in order for this to succeed, and if it succeeds it would benefit them all and mostly the citizens.

\section{References}

1. Patricia S.Abril and RobertPlant. 2007. The patent holder's dilemma: Buy, sell, or troll?Commun. ACM 50, 1 (Jan. 2007), 36-44. DOI:

http://dx.doi.org/10.1145/1188913.1188915 
2. I. F.Akyildiz, W.Su, Y.Sankarasubramaniam, and E.Cayirci. 2002. Wireless Sensor Networks: A Survey. Comm. ACM 38, 4 (2002), 393-422.

3. David A.Anisi. 2003. Optimal Motion Control of a Ground Vehicle. Master's thesis. Royal Institute of Technology (KTH), Stockholm, Sweden.

4. P.Bahl, R.Chancre, and J.Dungeon. 2004. SSCH: Slotted Seeded Channel Hopping for Capacity Improvement in IEEE 802.11 Ad-Hoc Wireless Networks. InProceeding of the 10th International Conference on Mobile Computing and Networking (MobiCom'04). ACM, New York, NY, 112-117.

5. Kenneth L.Clarkson. 1985. Algorithms for Closest-Point Problems (Computational Geometry). Ph.D. Dissertation. Stanford University, Palo Alto, CA. UMI Order Number: AAT 8506171.

6. JacquesCohen (Ed.). 1996. Special Issue: Digital Libraries. Commun. ACM 39, 11 (Nov. 1996).

7. Bruce P.Douglass. 1998. Statecarts in use: structured analysis and object-orientation. In Lectures on Embedded Systems, GrzegorzRozenberg and Frits W. Vaandrager (Eds.). Lecture Notes in Computer Science, Vol. 1494. Springer-Verlag, London, 368-394. DOI: http://dx.doi.org/10.1007/3-540-65193-429

8. IanEditor (Ed.). 2008. The title of book two (2nd. ed.). University of Chicago Press, Chicago, Chapter 100. DOI: http://dx.doi.org/10.1007/3-540-09237-4

9. Lawrence Rosen (2004). Open Source Licensing, Software Freedom and Intellectual Property Law. Prentice Hall.

10. Kenneth Wong and Phet Sayo (2004). FOSS A General Introduction. International Open Source Network.

11. Andrew J. Hall (2015). Open Source Business Models: Making money by giving it away. The Linux Foundation.

12. Eric Raymond (2009). The Cathedral \& the Bazaar: Musings on Linux and Open Source by an Accidental Revolutionary. O'Reilly Media.

13. Chris DiBona and Sam Ockman (2008). Open Sources: Voices from the Open Source Revolution. O'Reilly Media.

14. Lydia Pintscher (2012). Open Advice: FOSS: What We Wish We Had Known When We Started. Lulu.

15. The National IT and Telecom Agency of Denmark (2009). Open Source Software and the Public Sector. The National IT and Telecom Agency.

16. Rishab Aiyer Ghosh (2005). CODE: Collaborative Ownership and the Digital Economy. The MIT Press.

17. Jordi Pueyio Busquets (4 December 2017). El Ayuntamiento de Barcelona rompe con el 'software' de Microsoft, El Pais

18. David A. Wheeler (2015). Why Open Source Software / Free Software (OSS/FS, FLOSS, or FOSS)? Look at the Numbers! https://www.dwheeler.com/oss_fs_why.html

19. Richard M. Stallman (2002). Free Software, Free Society: Selected Essays of Richard M. Stallman. GNU Press.

20. Amit Dua (2017). Linux is Running in Almost all of the Supercomputers. TechFAE, June 252017.

https://www.techfae.com/linux-running-almost-supercomputers/

21. Jim Gruen (2012). Linux in space. The Linux Foundation.

22. CERN. Linux @ CERN. http://linux.web.cern.ch/linux/install/ 
23. Christos Bouras, Vasileios Kokkinos, Georgia Tseliou (2011). Methodology for Public Administrators for selecting between open source and proprietary software. Telematics \& Informatics journal (www.elsevier.com)

24. Blackduck. The 7 Myths of IP Risk: The Real Exposure Issues with Free and Open Source Software. Black Duck Software White Paper. 